Research Article

\title{
Research on Pricing Decision of Direct Sales Green Supply Chain Based on Consumers' Valuation
}

\author{
Yong-Gang Ye $\mathbb{i}^{1,2}$ and Xiao-Feng Liu ${ }^{1}$ \\ ${ }^{1}$ School of Management, Harbin University of Commerce, Harbin, Heilongjiang 150028, China \\ ${ }^{2}$ School of Basic Science, Harbin University of Commerce, Harbin, Heilongiiang 150028, China \\ Correspondence should be addressed to Yong-Gang Ye; ye_yonggang@163.com
}

Received 26 August 2021; Revised 30 September 2021; Accepted 23 October 2021; Published 11 November 2021

Academic Editor: Daqing Gong

Copyright (c) 2021 Yong-Gang Ye and Xiao-Feng Liu. This is an open access article distributed under the Creative Commons Attribution License, which permits unrestricted use, distribution, and reproduction in any medium, provided the original work is properly cited.

\begin{abstract}
Consumer's valuation of merchandise is an important factor affecting consumer buying behavior. When the consumer's valuation exceeds the price of product, the consumer generally makes a decision to purchase the product; conversely, when the consumer's estimate is lower than the price of product, the consumer will usually refuse to buy the product. From the perspective of consumer product valuation, this study assumed that the consumer's product valuation obeys a uniform distribution, and a novel consumer demand function was proposed. On this basis, we studied enterprises' pricing decisions in the supply chain of green agricultural products and obtained the equilibrium prices and optimal profits of the enterprises in several different scenarios, including Vertical Nash game model (VNM), firm A Stackelberg game model (FASM), firm B Stackelberg game model (FBSM), and cooperative game model (CM). In addition, the influence of parameters, such as green level, green preference payment coefficient, and green cost on the optimal profit, was discussed based on game theory and numerical simulation analysis. It was found that equilibrium prices always existed in several different scenarios, and when consumer's green preference payment coefficient was large enough, the optimal profit of firm B was greater than the optimal profit of firm A. Furthermore, in CM, the sum of optimal profit of firm A and optimal profit of firm B is maximum for four scenarios. Finally, in the three competitive scenarios, green level, green preference payment coefficient, and green cost, have a positive or negative effect on the optimal profits of firm A or firm B. The research conclusions of this study provided theoretical support for the decision-making of enterprises and related management departments.
\end{abstract}

\section{Introduction}

In recent years, the ecosystems globally have been severely affected by excessive human production activities [1]. The environmental pressures for human existence are getting worse. To reduce the current environmental pressure and improve the global ecosystem, more and more scholars and enterprises are paying attention to the green supply chain management (GSCM) [2-6]. Because the consumer green awareness was one of the main factors that have influenced the research of researchers and practitioners on green supply chain (GSC) [7], more and more countries and relevant institutions are also trying various methods to raise the consumer green awareness [8]. With the continuous improvement in consumer green awareness, the effect of consumer green awareness on demand is becoming research stream $[9,10]$. Meanwhile, agriculture is the foundation of national economic and social stability, and the basis of human existence. With the increase in purchasing power and green awareness, consumers will prefer to buy greener agricultural produce as part of their daily diet. Green and healthy agricultural produce is becoming the common expectation of all consumers around the world. Therefore, considering consumer green awareness, the research on the management of green agricultural products supply chain is of great practical significance.

On the other hand, with the business motives of increasing revenues, in order to increase the competitiveness of the agricultural enterprises, agricultural plantation firms are more interested in green production research and 
practices. The following four issues have attracted the attention of researchers and practitioners towards the green agriculture supply chain management: (1) How environmental awareness and level of green affect demand functions? (2) Whether the enterprise has the motivation to produce green agricultural products? (3) How the product is priced? (4) What measures can the government take to effectively promote green agriculture development?

In order to answer the abovementioned questions, in this study, the researchers propose game models in GSC including two farm produce plantation firms, their own directoperated retailers and consumers, and study the price coordination and decision-making issues in the green supply chain. The contribution of this study is shown in the construction of a new nonlinear demand function with respect to retail price and greening level from the perspective of consumers merchandise valuation and applying it to the coordinated analysis of green agriculture supply chain. This study also aimed to provide suggestions for enterprises and government decision-making departments.

The following content of this study is as follows. Section 2 is literature review. Section 3 is to build the models. Section 4 gives the equilibrium prices and the optimal profits under different scenarios. Section 5 analyzes the results of Section 4. Section 6 provides the results of the numerical analysis. Section 7 gives the conclusion and future research issues.

\section{Literature Review}

This study is related to the GSC coordinate research, including substitutable products and green preference consumers. Next, we will introduce the recent related literature on this area.

The formal GSCM concept was gradually taken shape after the 1990s [11]. The related literature such as that of Zhang et al. [12] made a review about green design by introducing "environmentally conscious design and manufacturing.” Fleischmann et al. [13] studied the problem of reverse logistics. Beamon [14] studied the issues of supply chain environmental management strategy. Since 2000, there are more and more researches on the literature review of GSC. For example, Srivastava [15] has carried out a comprehensive and brand-new research on GSCM from the perspective of the concept of reverse logistics using the abundant available literature. Seuring and Müller [11] made a literature review of 191 articles on sustainable supply chain management and discussed the specific characteristics and limitations of the research objects. Sarkis et al. [2] classified recent GSCM documents into nine categories, giving research opportunities, directions, and future GSCM issues worthy of research. Luthra et al. [16] outlined many issues related to GSCM and proposed the direction of further research on GSCM. Tseng et al. [6] reviewed the GSCM literature published from 1998 to 2017 and proposed directions and insights of future research.

As one of the main research contents of GSC, the research on GSC coordination has attracted more and more scholars' attention, many related literatures have studied channel coordination based on the framework of game theory. Jeuland and Shugan [17] discussed the problem of channel coordination in the GSC, including a manufacturer and a retailer, and solved nine problems related to channel coordination. Choi [18] studied the manufacturer-Stackberg game, the retailer-Stackberg game, and the vertical Nash game for the GSC of two competing manufacturers and an ordinary retailer selling the products of these two manufacturers. Ghosh and Shah [3] studied GSC coordination issues based on the models of the last study and analyzed how greening level, prices, and profits are affected by channel structure. Furthermore, Yang and Xiao [10] considered the fuzzy uncertainty of consumer demand and manufacturing costs; for three different channel leadership scenarios, the coordination problem of green supply chains with government intervention is studied. In the duopoly green supply chain of vertical and horizontal competition, Chen et al. [19] studied the optimal decision problems of the GSC under the different market power scenarios of channel members. Song and Gao [5] considered revenue sharing contracts in GSC and established a Nash bargaining game model to study the GSCM coordination problem. During a single sales period, Raza and Govindaluri [20] studied the coordination problem of a supply chain consisting of a manufacturer and a retailer under integrated and decentralized conditions.

In the existing studies on GSC channel coordination, the demand is usually linear function and depends on the retail price and product green level. In addition, the demand function is sometime deterministic or stochastic. Ghosh and Shah [3] studied the coordination of GSC channels under several different power structure scenarios and compared the optimal pricing and green decision-making of supply chain participants in each structure when demand was linear and deterministic function depending on the retail price and product green quality. Swami and Shah [9] studied the coordination of GSC involving a retailer and a manufacturer, the demand function was linear and deterministic, and it depended on the retail price, greening effort. Based on fuzzy and uncertain consumer demand and manufacturing costs, Yang and Xiao [10] proposed three game models with government intervention in the GSC and studied how channel power structure and government intervention affect optimal prices, green levels, and profits. Song and Gao [5] studied the optimal decision of GSC with two revenuesharing contracts when demand was linear and deterministic function depending on the retail price and greening level. When the demand function is linear and stochastic, and depends on retail prices and greening efforts, Raza and Govindaluri [20] studied the coordination of a singlechannel GSC.

Our work proposes game theoretic models in green supply chain including two farm produce plantation firms and their own retailers; it is different from previous studies; we construct a novel demand function from the perspective of consumers merchandise valuation, and the demand function is nonlinear and deterministic with respect to retail price and greening level. On the basis of the demand function, we analyzed and compared the optimal pricing strategy in Vertical Nash game model (VNM), firm A 
Stackelberg game model (FASM), firm B Stackelberg game model (FBSM), and cooperative game model (CM); in addition, the effect of main parameters (green level, green preference, green cost) on the optimal profit is analyzed.

\section{The Model Development}

When Marshall put forward the concept of consumer surplus, he believed that the price paid by consumers when purchasing merchandises would never be higher than the price they would rather pay [21]. Therefore, this study considers the price that consumers would rather pay when purchasing farm produce as merchandise valuation. When the price of farm produce is not higher than the merchandise valuation, the consumer will purchase farm produce. Otherwise, when the price of farm produce is higher than the merchandise valuation, the consumer will refuse to purchase the farm produce. From this point of view, this study proposed a novel consumer demand function and discussed the optimal decision-making problem when the company adopts different production strategies in an oligopoly market with only two agricultural plantation firms.

\subsection{Model Assumptions and Parameters}

3.1.1. Model Assumptions. In order to simplify the analysis of the model, the following assumptions were made based on literatures $[10,22]$ :

Assumption 1. The supply chain structure (as shown in Figure 1) comprises two farm produce plantation firms and their own retailers, firm A plant nongreen produce and firm $B$ plant green produce, and the farm produce plantation firm is also the retailer; the firm's product pricing is the selling price of the retailers.

Assumption 2. It is assumed that the market potential is unit 1 .

Assumption 3. In the model, the marginal and fixed costs of nongreen produce are not considered, namely, it is assumed that marginal and fixed cost are both zero; moreover, the transport costs and advertising costs are ignored; the unit costs of green produce is assumed to be bg.

Assumption 4. The consumers' valuation of nongreen produce in the market is subjected to uniform distribution in [ $\left.p_{\min }, p_{\max }\right]$; the consumers' valuation of green produce in the market is subjected to uniform distribution in $\left[p_{\min }, p_{\max }+a g\right]$; in the model, for simplicity, let the value of $p_{\min }$ be zero. In other words, the $x(x \in[0,1])$ position consumers' valuation of nongreen produce is $x p_{\max }$, and the $x(x \in[0,1])$ position consumers' valuation of green produce is $x\left(p_{\max }+a g\right)$.

Assumption 5. It is assumed that if the greenness of the produce is not considered, the produce is completely

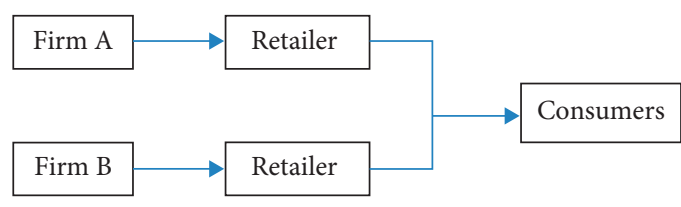

Figure 1: Structure of the supply chain.

homogeneous, and the consumers are very sensitive to selling price of the retailers.

3.1.2. Parameter Symbols Description. The symbols in the model are summarized as shown in Table 1.

\subsection{Proposed Model}

3.2.1. Proposed Demand Function. According to Assumption 5, the consumers are sensitive to retail price. When the retail price of both products does not exceed the consumer's valuation of the produce, consumers are willing to buy the product with a greater difference between valuation and retail price. Therefore, let $x$ denote potential consumer in the market, then his valuation of nongreen products is $x p_{\max }$, and his valuation of green products is $x\left(p_{\max }+a g\right)$.

Thus, if $x>p_{2} /\left(p_{\max }+a g\right)$ and $x\left(p_{\max }+a g\right)-p_{2}>$ $x p_{\max }-p_{1}$, that is $x>p_{2} /\left(p_{\max }+a g\right)$ and $x>\left(p_{2}-p_{1}\right) / a g$, the consumer buys green product.

If $x>p_{1} / p_{\max }$ and $x\left(p_{\max }+a g\right)-p_{2}<x p_{\max }-p_{1}$, that is $x>p_{1} / p_{\max }$ and $x<\left(p_{2}-p_{1}\right) / a g$, the consumer buys nongreen product.

Therefore, the market demand functions are the following situations.

(1) If $\left(p_{2}-p_{1}\right) / a g>1$, due to $0 \leq x \leq 1$, now $x<\left(p_{2}-p_{1} / a g\right)$, the demand functions are given as follows:

$$
\begin{aligned}
& q_{1}=1-\frac{1}{p_{\max }} p_{1}, \\
& q_{2}=0 .
\end{aligned}
$$

(2) If $\left(p_{2}-p_{1}\right) / a g<1$, there are 3 ! $=6$ sorts for $p_{1} / p_{\max }$, $p_{2} /\left(p_{\max }+a g\right)$ and $\left(p_{2}-p_{1}\right) / a g$ from small to large; after the merger, the demand functions are given as the following three results:

(i) If $\left(p_{2}-p_{1}\right) / a g<1$, and $\left(p_{2}-p_{1}\right) / a g>\max$ $\left\{p_{1} / p_{\max }, p_{2} /\left(p_{\max }+a g\right)\right\}$, the demand functions are as follows:

$$
\begin{aligned}
& q_{1}=\frac{p_{2}-p_{1}}{a g}-\frac{p_{1}}{p_{\max }}, \\
& q_{2}=1-\frac{p_{2}-p_{1}}{a g} .
\end{aligned}
$$

(ii) If $\left(p_{2}-p_{1}\right) / a g<1$, and $p_{2} /\left(p_{\max }+a g\right)>\max$ $\left\{p_{1} / p_{\max },\left(p_{2}-p_{1}\right) / a g\right\}$, the demand functions are as follows: 
Table 1: Parameter symbols and description.

\begin{tabular}{|c|c|}
\hline Symbols & Description \\
\hline$p_{1}$ & Retail price per unit produce of firm A \\
\hline$p_{1 j}^{*}$ & Equilibrium retail price per unit produce of firm $\mathrm{A}$ under the $j$ th condition \\
\hline$p_{2}$ & Retail price per unit produce of firm B \\
\hline$p_{2 j}^{*}$ & Equilibrium retail price per unit produce of firm B under the $j$ th condition \\
\hline$q_{1}$ & Market demand for firm A's produce \\
\hline$q_{2}$ & Market demand for firm B's produce \\
\hline$g$ & Green level of firm B's produce, and its value range is $0 \leq g \leq 1$ \\
\hline$p_{\max }$ & Consumers' highest valuation of nongreen produce \\
\hline$p_{\min }$ & Consumers' lowest valuation of nongreen produce, and $p_{\min }=0$ \\
\hline$a$ & Consumer's green preference payment coefficient for green produce \\
\hline$b$ & Green cost for per unit green produce \\
\hline$\pi_{1}$ & Firm A's profit function \\
\hline$\pi_{1 j}^{*}$ & Firm A's optimal profit under the $j$ th scenario \\
\hline$\pi_{2}^{1 /}$ & Firm B's profit function \\
\hline$\pi_{2 j}^{*}$ & Firm B's optimal profit under the $j$ th scenario \\
\hline
\end{tabular}

$$
\begin{aligned}
& q_{1}=\frac{p_{2}}{p_{\max }+a g}-\frac{p_{1}}{p_{\max }}, \\
& q_{2}=1-\frac{p_{2}}{p_{\max }+a g} .
\end{aligned}
$$

(iii) If $\left(p_{2}-p_{1}\right) / a g<1$, and $p_{1} / p_{\max }>\max$ $\left\{p_{2} /\left(p_{\max }+a g\right),\left(p_{2}-p_{1}\right) / a g\right\}$, the demand functions are as follows:

$$
\begin{aligned}
& q_{1}=0, \\
& q_{2}=1-\frac{p_{2}}{p_{\max }+a g} .
\end{aligned}
$$

In the above cases, only when $p_{2}-p_{1} / a g<1$ and $\left(p_{2}-p_{1}\right) / a g>\max \left\{p_{1} / p_{\max }, p_{2} /\left(p_{\max }+a g\right)\right\}$, there are the equilibrium results. The proofs are given in Appendix A. To sum up, the analytical results for demand functions are shown in Table 2.

3.2.2. Proposed Model. It can be seen from Table 2, when the equilibrium results exists, the demand functions are as

$$
\begin{aligned}
& q_{1}=\frac{p_{2}-p_{1}}{a g}-\frac{p_{1}}{p_{\max }} \\
& q_{2}=1-\frac{p_{2}-p_{1}}{a g} .
\end{aligned}
$$

Then, the profit functions of firms are given as

$$
\begin{aligned}
& \pi_{1}\left(p_{1}\right)=p_{1} q_{1}=p_{1}\left(\frac{p_{2}-p_{1}}{a g}-\frac{p_{1}}{p_{\max }}\right) \\
& \pi_{2}\left(p_{2}\right)=\left(p_{2}-b g\right) q_{2}=\left(p_{2}-b g\right)\left(1-\frac{p_{2}-p_{1}}{a g}\right) .
\end{aligned}
$$

\section{Equilibrium Prices and Optimal Profit under Different Scenarios}

In this section, we discuss the equilibrium prices and optimal profits of firm A and firm B based on noncooperative game and cooperative game theory in four scenarios: Vertical Nash game model (VNM), firm A Stackelberg game model (FASM), firm B Stackelberg game model (FBSM), and cooperative game model (CM).

4.1. Equilibrium Prices and Optimal Profit in VNM. In VNM, assume that neither firm A nor firm B can dominate the market, and they make their decisions simultaneously.

Due to $\partial^{2} \pi_{1} / \partial p_{1}^{2}=-2\left(1 / \operatorname{ag}_{2}+1 / p_{\max }\right)<0$, and $\partial^{2} \pi_{2} / \partial p_{2}^{2}=-2 / \operatorname{ag}_{2}<0$, the firm $A$ 's profit function is strictly concave in $p_{1}$, and the firm B's profit function is strictly concave in $p_{2}$.

Let the first derivative of the profit function equal to 0 , respectively, we get

$$
\left\{\begin{array}{l}
\frac{\partial \pi_{1}}{\partial p_{1}}=\frac{p_{2}-2 p_{1}}{a g}-\frac{2 p_{1}}{p_{\max }}=0 \\
\frac{\partial \pi_{2}}{\partial p_{2}}=1+\frac{p_{1}-2 p_{2}+b g}{a g}=0 .
\end{array}\right.
$$

Solving the system of equations, we get

$$
\begin{aligned}
& p_{11}^{*}=\frac{(a+b) g p_{\max }}{3 p_{\max }+4 a g}, \\
& p_{21}^{*}=\frac{2 g(a+b)\left(p_{\max }+a g\right)}{3 p_{\max }+4 a g} .
\end{aligned}
$$

Substituting equations (9) and (10) into equations (6) and (7), we get 
TABLe 2: Analytical results for demand functions under several different conditions.

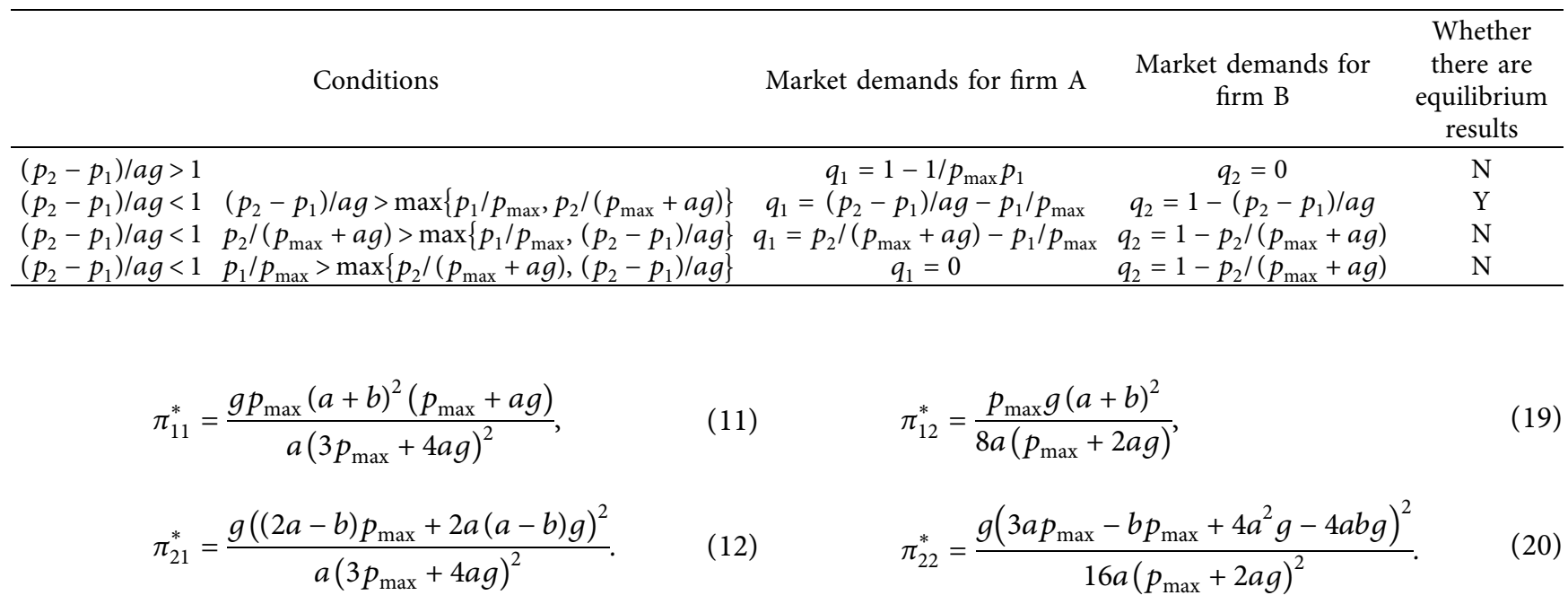

4.2. Equilibrium Prices and Optimal Profit in FASM. In FASM, it assumes that the market is controlled by firm A, which is Stackelberg leader, and time sequence of the game is as follows:

(1) First, the firm A decides the retail price of unit produce

(2) After observing the retail price of firm A's produce, the firm $B$ decides its retail price of unit produce

This model can be solved by backward induction. First, let the first derivative of equations (7) equal to 0 , then we get

$$
\frac{\partial \pi_{2}}{\partial p_{2}}=1+\frac{p_{1}-2 p_{2}+b g}{a g}=0 .
$$

Solving the equation, we get

$$
p_{2}=\frac{p_{1}}{2}+\frac{(a+b)}{2} g \text {. }
$$

Second, we substitute the value of $p_{2}$ into the above equations (6) and let the first derivative equal to 0 , we get

$$
\frac{\partial \pi_{1}}{\partial p_{1}}=-\frac{2 p_{1}}{p_{\max }}-\frac{p_{1}}{a g}+\frac{(a+b) g}{2 a g}=0 .
$$

Solving the equation, we get

$$
p_{1}=\frac{(a+b) g p_{\max }}{2\left(p_{\max }+2 a g\right)} \text {. }
$$

From the above, we get

$$
\begin{aligned}
& p_{12}^{*}=\frac{(a+b) g p_{\max }}{2\left(p_{\max }+2 a g\right)}, \\
& p_{22}^{*}=\frac{g(a+b)\left(3 p_{\max }+4 a g\right)}{4\left(p_{\max }+2 a g\right)} .
\end{aligned}
$$

Substituting equations (17) and (18) into equations (6) and (7), we get
4.3. Equilibrium Prices and Optimal Profit in FBSM. In this scenario, it assumes that firm B is a Stackelberg leader, and time sequence of the game is as follows:

(1) First, the firm B decides the retail price of unit produce

(2) After observing the retail price of firm B's produce, then the firm A decides its retail price of unit produce

We solve this game model by backwards induction. First, let the first derivative of equations (6) equal to 0 , we get

$$
\frac{\partial \pi_{1}}{\partial p_{1}}=-\frac{p_{1}}{p_{\max }}-p_{1}\left(\frac{1}{p_{\max }}+\frac{1}{a g}\right)+\frac{\left(p_{2}-p_{1}\right)}{a g}=0 .
$$

Solving the equation, we get

$$
p_{1}=\frac{p_{\max } p_{2}}{2\left(p_{\max }+a g\right)} \text {. }
$$

Second, we substitute the value of $p_{1}$ into the above equations (7) and let the first derivative of equal to 0 , we get

$$
\frac{\partial \pi_{2}}{\partial p_{2}}=1-\frac{p_{\max } p_{2}+a\left(2 g p_{2}-b g^{2}\right)-b g p_{\max } / 2}{a g\left(p_{\max }+a g\right)}=0 \text {. }
$$

Solving the equation, we get

$$
p_{2}=a g+\frac{b g}{2}-\frac{a^{2} g^{2}}{p_{\max }+2 a g} .
$$

From the above, we get

$$
\begin{aligned}
& p_{13}^{*}=\frac{p_{\max }\left(2 a^{2} g^{2}+2 a b g^{2}+2 a p_{\max } g+b p_{\max } g\right)}{4\left(p_{\max }+a g\right)\left(p_{\max }+2 a g\right)}, \\
& p_{23}^{*}=a g+\frac{b g}{2}-\frac{a^{2} g^{2}}{p_{\max }+2 a g} .
\end{aligned}
$$

Substituting equations (25) and (26) into equations (6) and (7), we get 


$$
\begin{aligned}
& \pi_{13}^{*}=\frac{p_{\max } g\left((2 a+b) p_{\max }+\left(2 a^{2}+2 a b\right) g\right)^{2}}{16 a\left(p_{\max }+2 a g\right)^{2}\left(p_{\max }+a g\right)}, \\
& \pi_{23}^{*}=\frac{g\left((2 a-b) p_{\max }+\left(2 a^{2}-2 a b\right) g\right)^{2}}{8 a\left(\left(2 a^{2} g^{2}+3 a g p_{\max }+p_{\max }^{2}\right)\right.} .
\end{aligned}
$$

4.4. Equilibrium Prices and Optimal Profit in CM. In this scenario, we discuss the equilibrium prices and optimal value of the sum function of the two profits. The sum function is given by

$$
\begin{aligned}
\pi & =\pi_{1}+\pi_{2}=p_{1}\left(\frac{p_{2}-p_{1}}{a g}-\frac{p_{1}}{p_{\max }}\right)+\left(p_{2}-b g\right) q_{2} \\
& =\left(p_{2}-b g\right)\left(1-\frac{p_{2}-p_{1}}{a g}\right) .
\end{aligned}
$$

Let the first derivative of sum function equal to 0 , respectively, we get

$$
\left\{\begin{array}{l}
\frac{\partial \pi}{\partial p_{1}}=-\frac{2 p_{1}-2 p_{2}+b g}{a g}-\frac{2 p_{1}}{p_{\max }}=0 \\
\frac{\partial \pi}{\partial p_{2}}=1+\frac{2 p_{1}-2 p_{2}+b g}{a g}=0 .
\end{array}\right.
$$

Solving the system of equations, we get

$$
\begin{aligned}
& p_{14}^{*}=\frac{p_{\max }}{2}, \\
& p_{24}^{*}=\frac{p_{\max }+a g+b g}{2} .
\end{aligned}
$$

Substituting equations (31) and (32) into equations (6) and (7), we get

$$
\begin{aligned}
& \pi_{14}^{*}=\frac{b p_{\max }}{4 a}, \\
& \pi_{24}^{*}=\frac{(a-b)\left(p_{\max }+a g-b g\right)}{4 a} .
\end{aligned}
$$

To sum up, the analytical results for equilibrium prices and optimal profit are shown in Table 3.

\section{Analysis of Results}

In this section, based on theoretical analysis methods, we compare the optimal values of profit functions, and the effect of key parameters on the optimal profit functions is discussed. The proofs are given in Appendix B.

\subsection{Profitability Analysis}

Proposition 1. In $V N M$, if $a>b-\left(p_{\max }-\sqrt{p_{\max }^{2}+4 b g p_{\max }}\right)$ $/ 2 g$, then $\pi_{11}^{*}<\pi_{21}^{*}$; In FASM, if $a>(2 \sqrt{5}+5) b / 5$, then $\pi_{12}^{*}<\pi_{22}^{*}$; In $C M$, if $a>b-\left(p_{\max }-\sqrt{p_{\max }^{2}+4 b g p_{\max }}\right) / 2 g$, then $\pi_{14}^{*}<\pi_{24}^{*}$; In FBSM, if $a>2 b$ and $4 b g-p_{\max }>0$, then $\pi_{13}^{*}<\pi_{23}^{*}$. Especially, for $a>2 b$, the optimal profit of firm $B$ is greater than the optimal profit of firm $A$ in the three scenarios of VNM, FASM, and CM.

Proposition 1 indicates that when the value of consumers' green preference payment coefficient a is large enough, especially, for $a>2 b$, the optimal profit of firm B usually is greater than the optimal profit of firm A. This result is consistent with intuitive cognition in real life. This shows that increasing consumer's green payment coefficient can improve the production enthusiasm of green production firm and promote the development of green agriculture. Therefore, measures such as green subsidy policies of relevant government departments or green consumption propaganda of related groups will definitely accelerate the development of green agriculture. In addition, it implied that at the three phases of development of the green agriculture, initial stage (FASM), middle stage (VNM), and later stage (FBSM), the condition that the optimal profit of firm B is greater than the optimal profit of firm $\mathrm{A}$ is getting higher and higher, namely, the enthusiasm of green production firm gradually decrease.

Proposition 2. In the three competitive scenarios of VNM, FASM, and FBSM, the optimal profit of firm $A$ is in the order $\pi_{11}^{*}<\pi_{12}^{*}<\pi_{13}^{*}$.

Proposition 2 indicate a comparison of the optimal profits of firm $\mathrm{A}$ in the three different scenarios of VNM, FASM, and FBSM; it shows that, in VNM, the value of firm A's optimal profit is minimum, the reason may be that the competition between the two firms is fiercer; interestingly, it is in FBSM instead of in FASM, the value of firm A's optimal profit is maximum; the reason may be that firm A makes a decision after firm B makes a decision. It implied that at the late stage of development of the green agriculture, nongreen planting firm is more motivated.

Proposition 3. In the three scenarios of VNM, FASM, and FBSM, the optimal profit of firm $B$ is in the order $\pi_{21}^{*}<\pi_{23}^{*}<\pi_{22}^{*}$.

The interpretation of Proposition 3 is similar to that of Proposition 2. It also implied that the production enthusiasm of green planting firm is smaller in the late stage than in the initial stage.

Proposition 4. The sum of optimal profit of firm $A$ and optimal profit of firm $B$ are in the order $\pi_{11}^{*}+\pi_{21}^{*}<\pi_{12}^{*}+$ $\pi_{22}^{*}<\pi_{14}^{*}+\pi_{24}^{*}$ and $\pi_{11}^{*}+\pi_{21}^{*}<\pi_{13}^{*}+\pi_{23}^{*}<\pi_{14}^{*}+\pi_{24}^{*}$. Proposition 4 shows that the sum of optimal profit of firm $A$ and optimal profit of firm $B$ is maximum in CM; it is equivalent to a firm plant's nongreen produce and green produce; therefore, this production mode has the strongest competitiveness, and the reason is that the competition between the two firms is weakest; the sum of optimal profit of firm $A$ and optimal profit of firm $B$ is minimum in VNM, and the reason is that the competition between the two firms is strongest. 


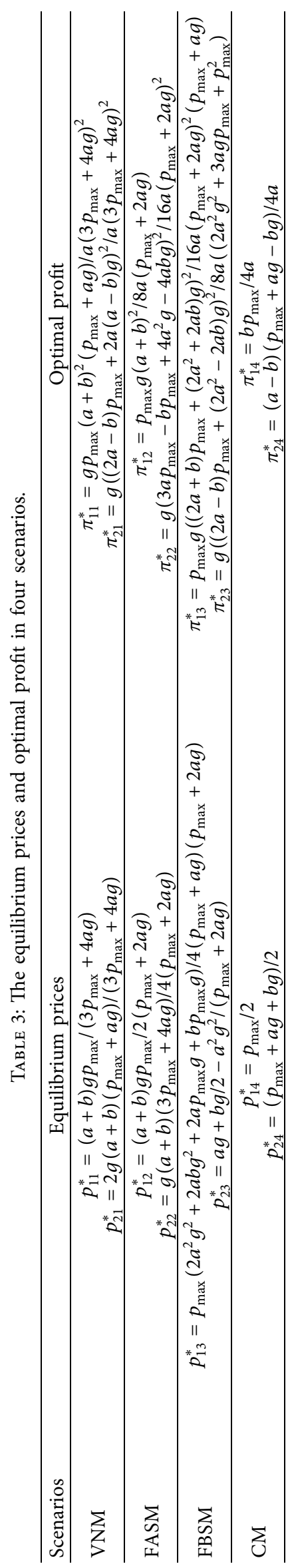




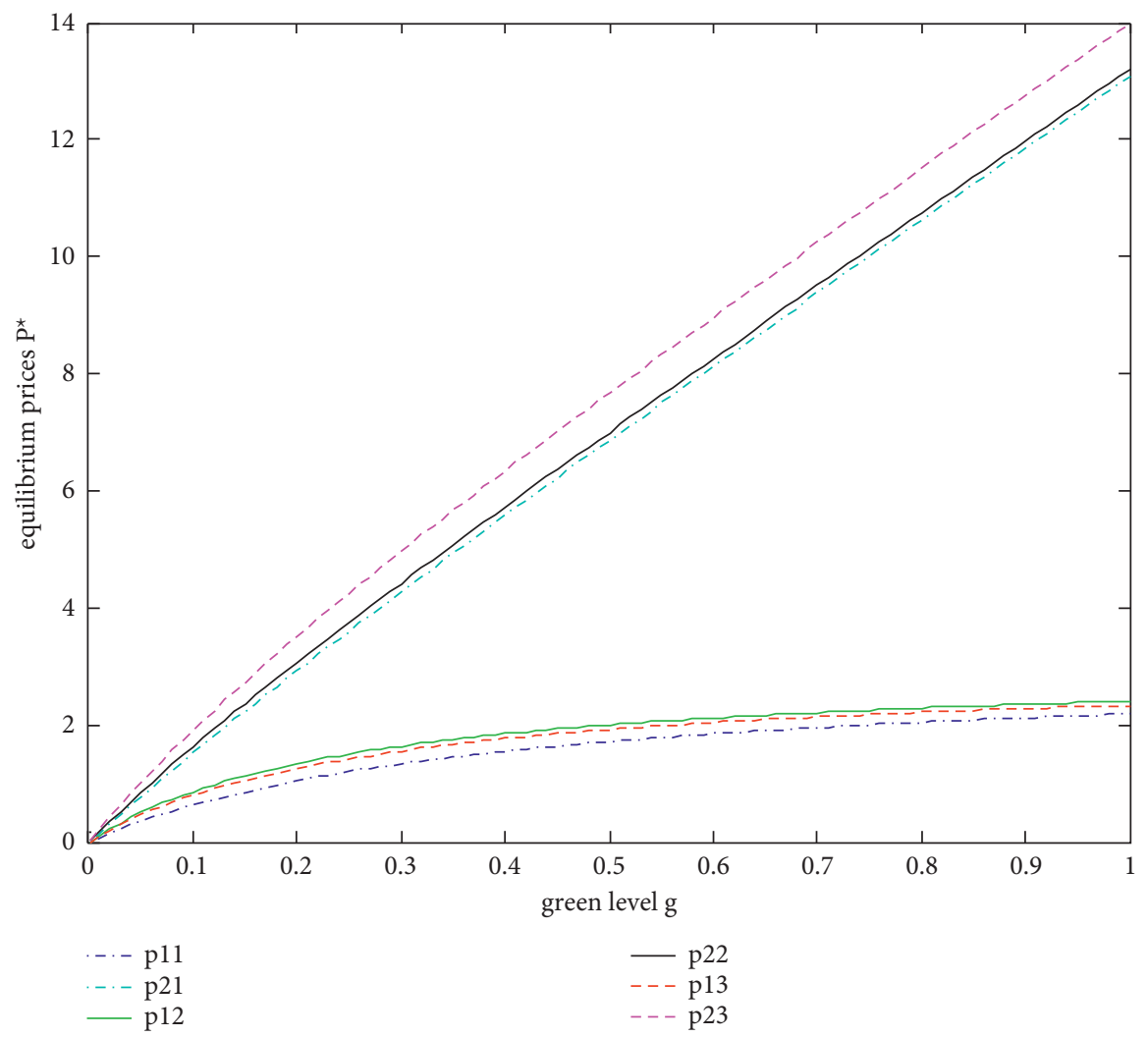

Figure 2: Equilibrium prices with green level.

\subsection{Analysis of Key Parameters}

Proposition 5. In the three competitive scenarios of VNM, FASM, and FBSM, the optimal profit of firm $A$ is monotonically increasing with respect to the level of green; for $a \geq 5 b / 3$, the optimal profits of firm $B$ are also monotonically increasing with respect to the level of green.

Proposition 5 shows that, in the three scenarios of VNM, FASM, and FBSM, the higher the level of green of firm B's produce, the greater the optimal profit of firm $A$; when $a \geq 5 b / 3$, it is the same conclusion for the optimal profit of firm B. It implies that when $a \geq 5 b / 3$, firm B will plant product with the highest level of green, and firm has the incentive to plant higher-level green produce.

Proposition 6. In three competitive scenarios of VNM, FASM, and FBSM, the optimal profit of firm B is monotonically increasing with respect to consumers' green preference payment coefficient a.

Proposition 6 shows that in the three scenarios of VNM, FASM, and FBSM, the larger the value of consumers' green preference payment coefficient, the greater the optimal profit of firm B. The result is consistent with intuitive cognition in real life. Therefore, the measures to increase green awareness of consumers are effective to improve green production enthusiasm.
Proposition 7. In the three competitive scenarios of VNM, FASM, and FBSM, the optimal profit of firm $A$ is monotonically increasing with respect to green cost $b$; the optimal profit of firm $B$ is monotonically decreasing with respect to green cost $b$.

Proposition 7 shows that in the three scenarios of VNM, FASM, and FBSM, the larger the value of green cost for per unit green produce, the smaller the optimal profit of firm B and the larger the optimal profit of firm A. This means the measures to decrease green cost for per unit green produce are effective to improve green production enthusiasm.

\section{Numerical Analysis}

In this section, we separately analyze the impact of the main parameters on the equilibrium prices and optimal profits in the three scenarios (VNM, FASM, and FBSM) by MATLAB software.

6.1. Numerical Analysis of Optimal Profits and Equilibrium Prices with Green Level. The following values were assumed: $p_{\max }=10, a=20, b=4, g \in[0,1]$, the simulation results shown in Figures 2 and 3.

6.2. Numerical Analysis of Optimal Profits and Equilibrium Prices with Green Preference. The following values were assumed: $p_{\max }=10, b=8, g=0.4$, a $\in[10,40]$, the simulation results shown in Figures 4 and 5. 


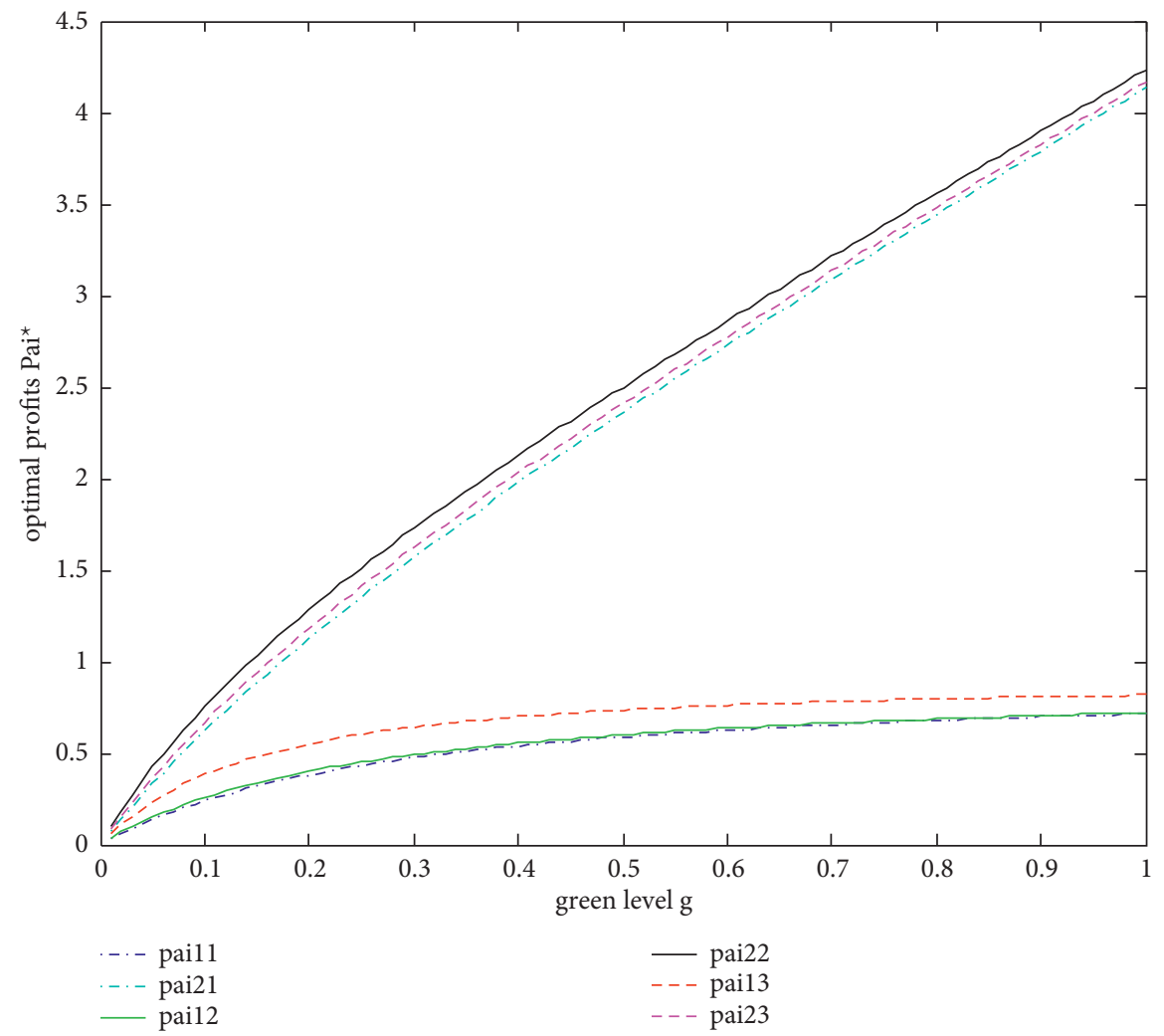

Figure 3: Optimal profits with green level.

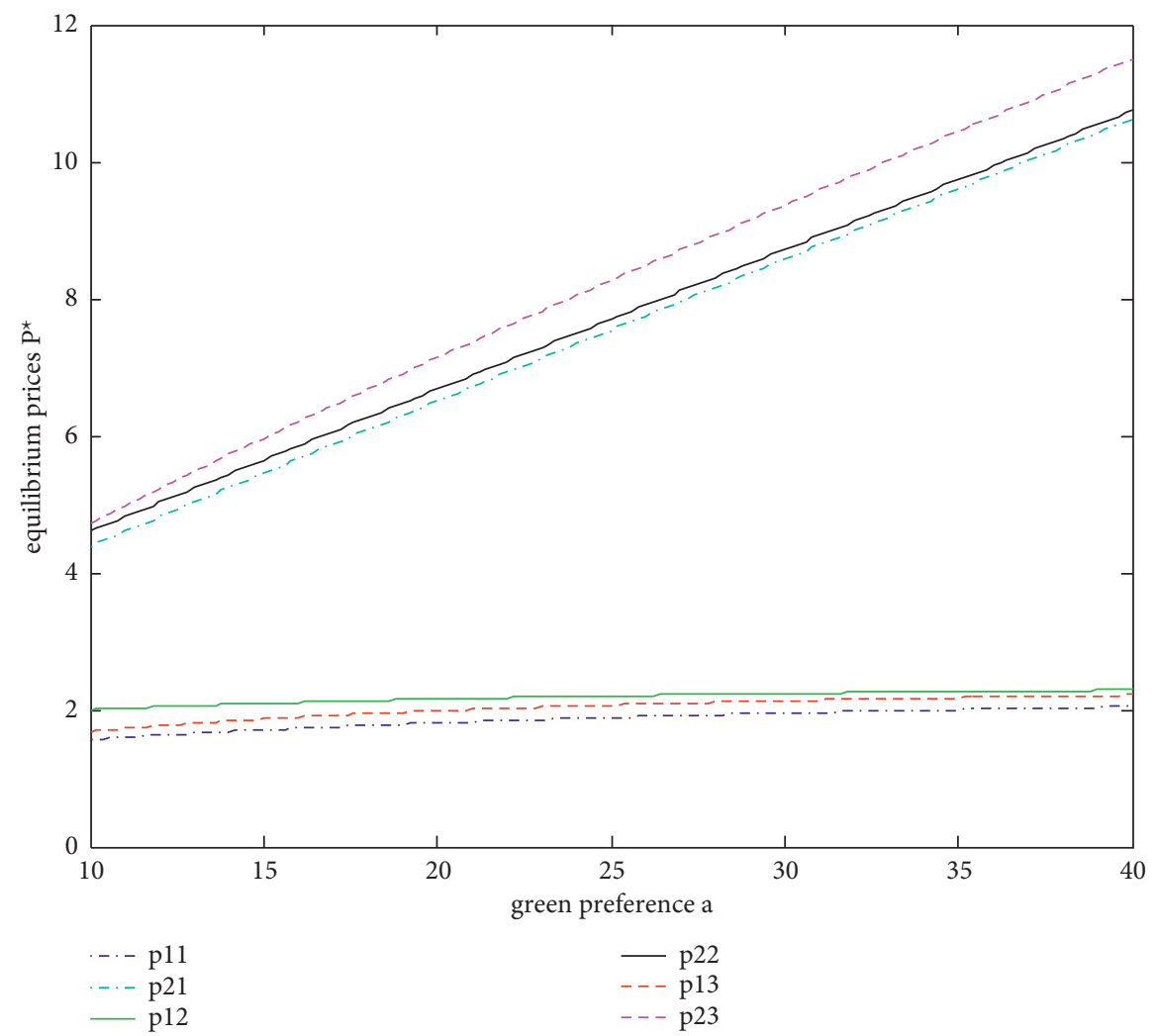

Figure 4: Equilibrium prices with green preference. 


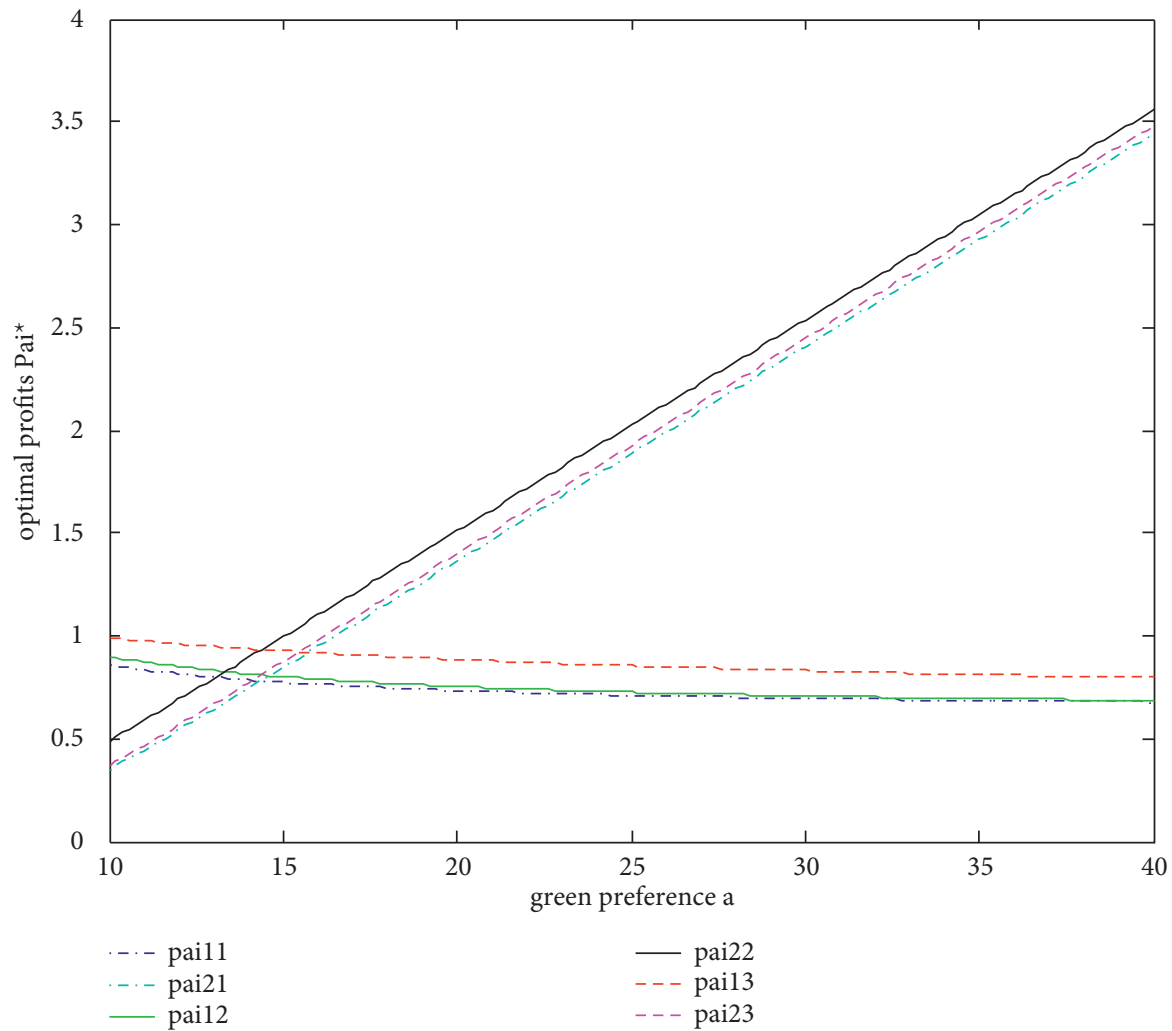

FIgURE 5: Optimal profits with green preference.

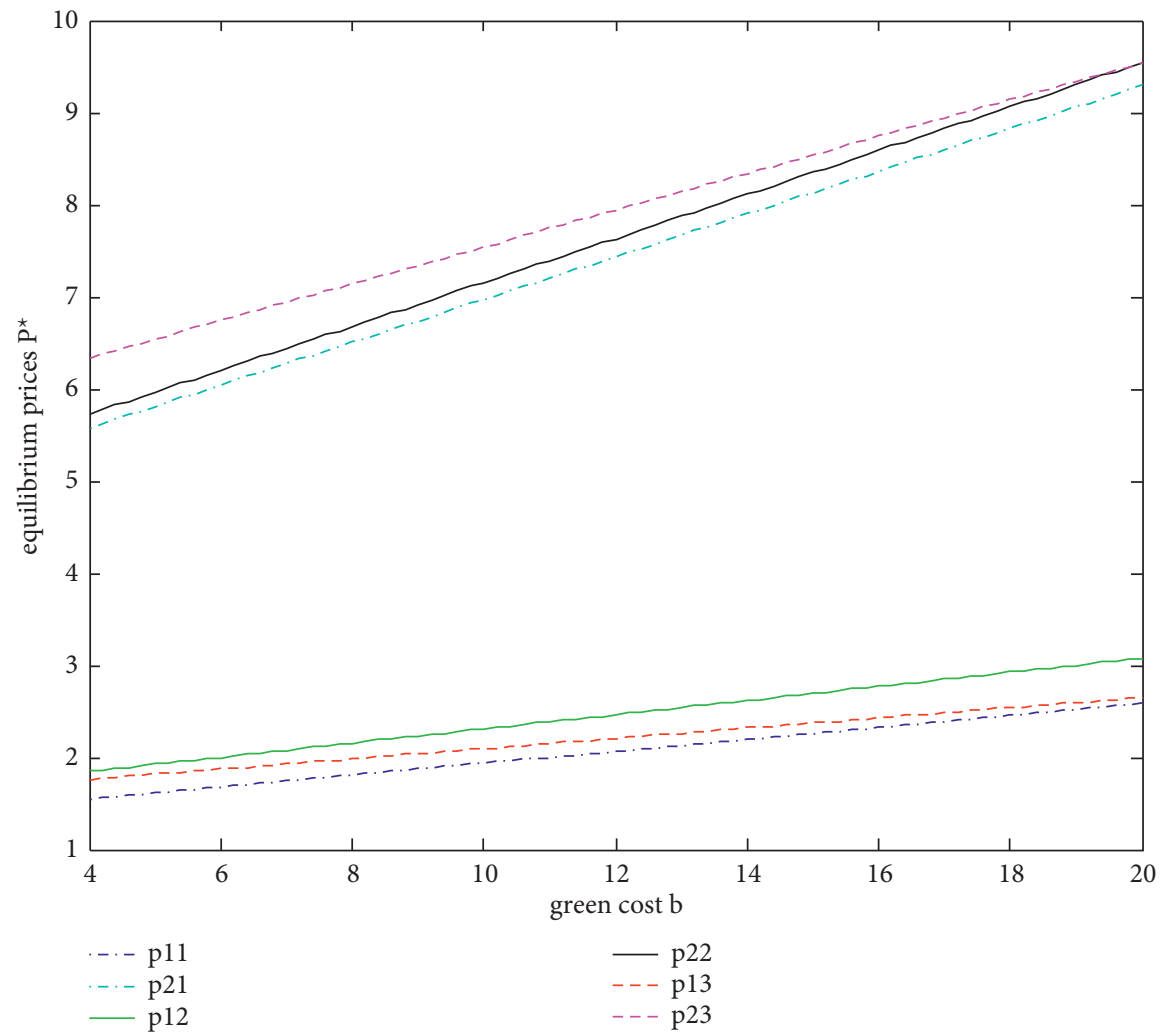

FIGURE 6: Equilibrium prices with green cost. 


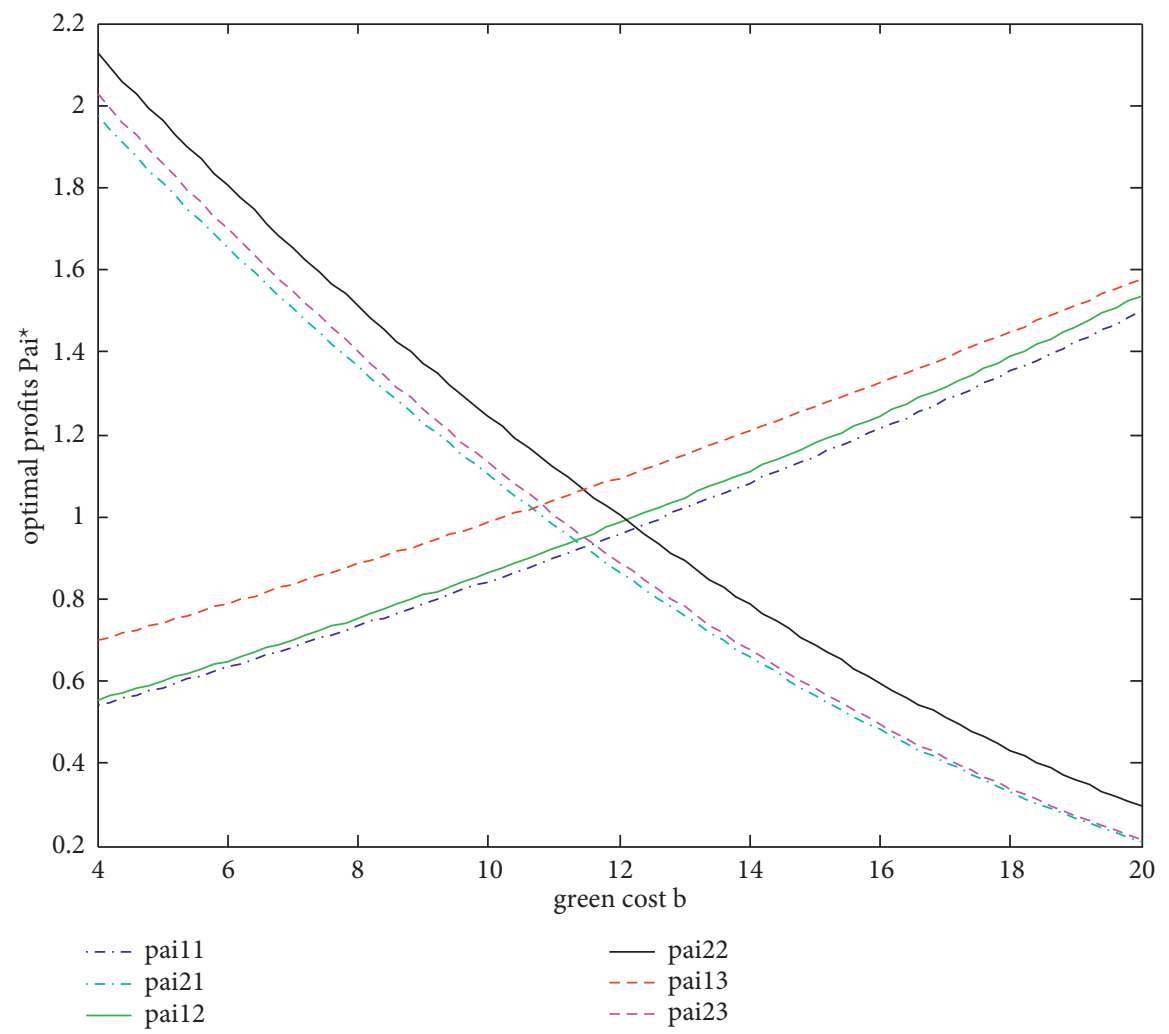

FIgURE 7: Optimal profits with green cost.

6.3. Numerical Analysis of Optimal Profits and Equilibrium Prices with Green Cost. The following values were assumed: $p_{\max }=10, a=20, g=0.4, b \in[4,20]$, the simulation results shown in Figures 6 and 7.

\section{Conclusion}

In the past research on the channel coordination of supply chain members, few have looked into the impact of consumers' merchandise valuation on demand function in GSC. In this study, from the perspective of consumers, a novel consumer demand function is proposed with the assumption that consumers' merchandise valuation is subject to uniform distribution. On this basis, the equilibrium pricing decision of firms are studied in four scenarios and compared the optimal profits under different scenarios; meanwhile, the effect of main parameters (green level, green preference, green cost) on the optimal profit is analyzed. Based on the results of the study, that the following was found. Firstly, in the initial stage of the development of green agriculture, it usually is in FASM scenario, the optimal profit of firm B is maximum in the three competitive scenarios, and if the ratio of consumer's green preference payment coefficient to green cost for per unit green produce is greater than a certain value, the optimal profit of firm $B$ is greater than the optimal profit of firm A; it implied that the production enthusiasm of green planting firm $\mathrm{B}$ is the highest under the above conditions; in the middle stage, it usually is in VNM scenario, and the optimal profits of firm A and firm B are the minimum; in the later stage, it usually is in FBSM scenario; if consumer's green preference payment coefficient is greater than twice green cost for per unit green produce, and the product of green cost for per unit green produce and green level is greater than one quarter of consumers' highest valuation of nongreen produce, the optimal profit of firm $B$ is greater than the optimal profit of firm A. It implied that firm is willing to grow green agricultural products under the above conditions, but the production enthusiasm has gradually decreased. Therefore, in order to maintain the enthusiasm of enterprises for green production, enterprises and related departments should continuously improve consumer's green preference payment coefficient or reduce green cost for per unit green produce. Secondly, if three times consumer's green preference payment coefficient is greater than five times green cost for per unit green produce, firm B will plant the highest green level product. Meanwhile, firm A will also get a higher optimal profit; it indicates that green agriculture will be able to develop further in a market economy. Thirdly, in CM, the sum of optimal profit of firm A and optimal profit of firm B is maximum for four scenarios; it shows that cooperation can achieve a win-win situation. Lastly, in the three competitive scenarios, the consumers' green preference payment coefficient has a positive effect on the optimal profits of firm B, and the green cost for per unit has a positive effect on the optimal profits of firm A, but the green cost for per unit has a negative effect on the optimal profits of firm B. It shows that in order to promote the development of green agriculture in China, it will be a very effective means to increase consumers' green awareness, design green consumption subsidy mechanism, reduce enterprises' green 
production costs, and design green production subsidy mechanism in a market economy. The practical significance of this study is to provide theoretical support for the decisionmaking of enterprises and related management departments and promote the development of green agriculture.

The study only selects product pricing as a decision variable, and the model in the study only considers the condition that consumers' valuations of produce are subject to a uniform distribution, so it can be extended into following two directions of further research: (1) In the model, consider that product pricing and greenness are both decision variables. (2) The models are built under the assumption that consumers' valuation of produce is subject to other distribution.

\section{Appendix}

\section{A. Proof of the Analytical Results for Demand Functions}

(1) For $\left(p_{2}-p_{1}\right) / a g>1$, the optimal solutions of the model are not equilibrium results.

Proof. At this time, because of $q_{2}=0$, the optimal profits of firm $B$ is zero; however, during the game between the two firms, even if the retail price per unit produce of firm $A$ is the minimum value of 0 , now, the market demand of firm $B$ is the smallest, and the retail price per unit produce of firm $B$ can still be selected $p_{2} \in(b g, a g)$, so $\left(p_{2}-p_{1}\right) / a g<1$, and the market demand of firm $B$ is more than zero; therefore, in this case, the optimal solutions of the model are not equilibrium results.

(2) For $\left(p_{2}-p_{1}\right) / a g<1$, and $\left(p_{2}-p_{1}\right) / a g>\max \left\{p_{1} /\right.$ $\left.p_{\max }, p_{2} /\left(p_{\max }+a g\right)\right\}$, the optimal solutions of the model are equilibrium results.

Proof. At this time, the profit functions of firm A and firm $\mathrm{B}$ are given as follows:

$\pi_{1}=p_{1} q_{1}=p_{1}\left(\frac{p_{2}-p_{1}}{a g}-\frac{p_{1}}{p_{\max }}\right)$,

$\pi_{2}=\left(p_{2}-b g\right) q_{2}=\left(p_{2}-b g\right)\left(1-\frac{p_{2}-p_{1}}{a g}\right)$.

Let the first derivative of profit functions to 0 , we get

$$
\begin{aligned}
& p_{1}^{*}=\frac{(a+b) g p_{\max }}{3 p_{\max }+4 a g}, \\
& p_{2}^{*}=\left(\frac{p_{\max }}{3 p_{\max }+4 a g}+1\right) \frac{(a+b) g}{2} .
\end{aligned}
$$

So,

$$
\begin{aligned}
p_{2}^{*}-p_{1}^{*} & =\left(\frac{p_{\max }}{3 p_{\max }+4 a g}+1\right) \frac{(a+b) g}{2}-\frac{(a+b) g p_{\max }}{3 p_{\max }+4 a g} \\
& =\frac{p_{\max }+2 a g}{3 p_{\max }+4 a g}(a+b) g .
\end{aligned}
$$

Then,

$$
\frac{p_{2}^{*}-p_{1}^{*}}{a g}=\frac{p_{\max } / a g+2}{3 p_{\max }+4 a g}(a+b) g .
$$

Now,

$$
\begin{gathered}
\frac{p_{1}^{*}}{p_{\max }}=\frac{1}{3 p_{\max }+4 a g}(a+b) g, \\
\frac{p_{2}^{*}}{p_{\max }+a g}=\left(\frac{2}{3 p_{\max }+4 a g}\right)(a+b) g .
\end{gathered}
$$

Obviously,

$$
\frac{p_{2}^{*}-p_{1}^{*}}{a g}>\frac{p_{2}^{*}}{p_{\max }+a g}>\frac{p_{1}^{*}}{p_{\max }} .
$$

Therefore, in this case, the optimal solutions of the model are equilibrium results.

(3) For $\left(p_{2}-p_{1}\right) / a g<1$ and $p_{2} /\left(p_{\max }+a g\right)>\max$ $\left\{p_{1} / p_{\max },\left(p_{2}-p_{1}\right) / a g\right\}$, the optimal solutions of the model are not equilibrium results.

Proof. At this time, the profit functions of firm A and firm B are given as follows:,

$$
\begin{aligned}
& \pi_{1}=p_{1} q_{1}=p_{1}\left(\frac{p_{2}}{p_{\max }+a g}-\frac{p_{1}}{p_{\max }}\right), \\
& \pi_{2}=\left(p_{2}-b g\right) q_{2}=\left(p_{2}-b g\right)\left(1-\frac{p_{2}}{p_{\max }+a g}\right) .
\end{aligned}
$$

Let the first derivative of profit functions to 0 , we get

$$
\begin{aligned}
& p_{1}^{*}=\frac{p_{\max }}{4}\left(1+\frac{b g}{p_{\max }+a g}\right), \\
& p_{2}^{*}=\frac{p_{\max }+a g}{2}\left(1+\frac{b g}{p_{\max }+a g}\right) .
\end{aligned}
$$

So,

$$
\begin{aligned}
p_{2}^{*}-p_{1}^{*}= & \frac{p_{\max }+a g}{2}\left(1+\frac{b g}{p_{\max }+a g}\right) \\
& -\frac{p_{\max }}{4}\left(1+\frac{b g}{p_{\max }+a g}\right) \\
= & \left(\frac{p_{\max }}{4}+\frac{a g}{2}\right)\left(1+\frac{b g}{p_{\max }+a g}\right) .
\end{aligned}
$$

Then,

$$
\frac{p_{2}^{*}-p_{1}^{*}}{a g}=\left(\frac{p_{\max }}{4 a g}+\frac{1}{2}\right)\left(1+\frac{b g}{p_{\max }+a g}\right) .
$$

Now, 


$$
\begin{array}{r}
\frac{p_{1}^{*}}{p_{\max }}=\frac{1}{4}\left(1+\frac{b g}{p_{\max }+a g}\right), \\
\frac{p_{2}^{*}}{p_{\max }+a g}=\frac{1}{2}\left(1+\frac{b g}{p_{\max }+a g}\right) .
\end{array}
$$

Obviously,

$$
\begin{gathered}
\frac{p_{2}^{*}-p_{1}^{*}}{a g}>\frac{p_{2}^{*}}{p_{\max }+a g}>\frac{p_{1}^{*}}{p_{\max }}, \\
\text { it Contradicts } \frac{p_{2}}{p_{\max }+a g}>\max \left\{\frac{p_{1}}{p_{\max }}, \frac{p_{2}-p_{1}}{a g}\right\} .
\end{gathered}
$$

Therefore, in this case, the optimal solutions of the model are not equilibrium results.

(4) For $\left(p_{2}-p_{1}\right) / a g<1$ and $p_{1} / p_{\max }>\max \left\{p_{2} /\left(p_{\max }+\right.\right.$ ag), $\left.\left(p_{2}-p_{1}\right) / a g\right\}$, the optimal solutions of the model are not equilibrium results.

Proof. At this time, because of $q_{1}=0$, the optimal profits of firm A is zero, however, during the game between the two firms, even if the retail price per unit produce of firm $B$ is the minimum value of $p_{2}=b g$, now, the market demand of firm $A$ is the smallest, and the retail price per unit produce of firm A can still be selected $p_{1} \in\left(0, b g / P_{\max }+a g\right)$, so the market demand of firm A is more than zero; therefore, in this case, the optimal solutions of the model are not equilibrium results.

\section{B. Proof of Proposition 1 to Proposition 7}

(1) Proofs of Proposition 1

(i) Proof. In VNM, based on equation (11) and equation (12), we know that,

$\pi_{21}^{*}-\pi_{11}^{*}=\frac{g\left(g(a-b)^{2}+a p_{\max }-2 b p_{\max }\right)}{3 p_{\max }+4 a g}$.

Let

$$
\frac{g\left(g(a-b)^{2}+a p_{\max }-2 b p_{\max }\right)}{3 p_{\max }+4 a g}>0 .
$$

We get,

$$
\begin{array}{r}
a>b-\frac{p_{\max }-\sqrt{p_{\max }^{2}+4 b g p_{\max }}}{2 g}, \\
\text { or } a<b-\frac{p_{\max }+\sqrt{p_{\max }^{2}+4 b g p_{\max }}}{2 g} .
\end{array}
$$

(Because $a>b$, it is abandoned.) In particular, for $a>2 b$, we get $\pi_{21}^{*}-\pi_{11}^{*}>0$.

Thus, in VNM, if $a>b-\left(p_{\max }-\right.$ $\left.\sqrt{p_{\max }^{2}+4 b g p_{\max }}\right) / 2 g$, or $a>2 b$, then $\pi_{11}^{*}<\pi_{21}^{*}$.

(ii) Proof. In FASM, based on equations (19) and (20), we know that

$$
\pi_{22}^{*}-\pi_{12}^{*}=\frac{g\left(7 a^{2}-10 a b-b^{2}\right) p_{\max }^{2}+4 a g^{2}\left(5 a^{2}-10 a b+b^{2}\right) p_{\max }+16 a^{2} g^{3}(a-b)^{2}}{16 a\left(p_{\max }+2 a g\right)^{2}}
$$

Because $a>b, \quad 7 a^{2}-10 \mathrm{a} b-b^{2}=5 a^{2}-10 \mathrm{a} b+$ $b^{2}+2 a^{2}-2 b^{2}>5 a^{2}-10 \mathrm{a} b+b^{2}$; obviously, if $5 a^{2}-10 \mathrm{a} b+b^{2}>0$, then $\pi_{22}^{*}-\pi_{12}^{*}>0$, solving the inequality, we get $a>(2 \sqrt{5}+5) b / 5$, or $a<(5-2 \sqrt{5}) b / 5$ (because $a>b$, it is abandoned). In particular, for $a>2 b$, we get $\pi_{22}^{*}-\pi_{12}^{*}>0$. Thus, in FASM, if $a>(2 \sqrt{5}+5) b / 5$, or $a>2 b$, then $\pi_{12}^{*}<\pi_{22}^{*}$.

(iii) Proof. In CM, based on equations (33) and (34), we know that

$$
\begin{aligned}
& \pi_{24}^{*}-\pi_{14}^{*}= \frac{g(a-b)^{2}+(a-2 b) p_{\max }}{4 a}, \\
& \text { let } \frac{g(a-b)^{2}+(a-2 b) p_{\max }}{4 a}>0 .
\end{aligned}
$$

We get

$$
\begin{gathered}
a>b-\frac{p_{\max }-\sqrt{p_{\max }^{2}+4 b g p_{\max }}}{2 g}, \\
\text { or } a<b-\frac{p_{\max }+\sqrt{p_{\max }^{2}+4 b g p_{\max }}}{2 g} .
\end{gathered}
$$

(Because $a>b$, it is abandoned.) Especially, for $a>2 b$, we get $\pi_{14}^{*}<\pi_{24}^{*}$.

Thus, in CM, if $a>b-\left(p_{\max }-\right.$ $\left.\sqrt{p_{\max }^{2}+4 b g p_{\max }}\right) / 2 g$, or $a>2 b$, then $\pi_{14}^{*}<\pi_{24}^{*}$.

(iv) Proof. In FBSM, based on equations (27) and (28), we know that 


$$
\pi_{23}^{*}-\pi_{13}^{*}=\frac{16 a^{3}(a-b)^{2} g^{4}+4 a^{2} p_{\max }(3 a-b)(3 a-5 b) g^{3}+4 a p_{\max }^{2}(a-2 b)(6 a-b) g^{2}+p_{\max }^{3}\left(4 a^{2}-12 a b+b^{2}\right) g}{16 a\left(p_{\max }+a g\right)\left(p_{\max }+2 a g\right)^{2}}
$$

For $a=2 b$, we get

$$
\pi_{23}^{*}-\pi_{13}^{*}=\frac{b^{2} g\left(4 b g-p_{\max }\right)\left(32 b^{2} g^{2}+28 b g p_{\max }+7 p_{\max }^{2}\right)}{32 b\left(p_{\max }+2 b g\right)\left(p_{\max }+4 b g\right)^{2}}
$$

Obviously, if $4 b g-p_{\max }>0$, then $\pi_{23}^{*}-\pi_{13}^{*}>0$. In addition, for $a \geq 2 b, \pi_{23}^{*}-\pi_{13}^{*}$ is monotonically increasing with respect to $a$. Thus, in FBSM, if $a>2 b$, and $4 b g-p_{\max }>0$, then $\pi_{23}^{*}-\pi_{13}^{*}>0$.

In summary, the Proposition 1 holds.
Proof. Equation (19) minus equation (11), we get

$$
\pi_{12}^{*}-\pi_{11}^{*}=\frac{g p_{\max }^{3}(a+b)^{2}}{8 a\left(3 p_{\max }+4 a g\right)^{2}\left(p_{\max }+2 a g\right)}>0
$$

Equation (27) minus equation (11), we get

(2) Proofs of Proposition 2

$$
\pi_{13}^{*}-\pi_{11}^{*}=\frac{g p_{\max }^{2}\left((2 a-b) p_{\max }+2 a(a-b) g\right)\left(16(a+b) a^{2} g^{2}+(26 a+22 b) a g p_{\max }+(10 a+7 b) p_{\max }^{2}\right)}{16 a\left(p_{\max }+a g\right)\left(p_{\max }+2 a g\right)^{2}\left(3 p_{\max }+4 a g\right)^{2}} .
$$

Because $a>b, \pi_{13}^{*}-\pi_{11}^{*}>0$.

Equation (27) minus equation (19), we get

$\pi_{13}^{*}-\pi_{12}^{*}=\frac{g p_{\max }^{2}\left(2 a g\left(a^{2}-b^{2}\right)+\left(2 a^{2}-b^{2}\right) p_{\max }\right)}{16 a\left(p_{\max }+a g\right)\left(p_{\max }+2 a g\right)^{2}}$.
Because $a>b, \pi_{13}^{*}-\pi_{12}^{*}>0$.

In summary, we know $\pi_{11}^{*}<\pi_{12}^{*}<\pi_{13}^{*}$.

(3) Proofs of Proposition 3

Proof. Equation (20) minus equation (12), we get

$$
\pi_{22}^{*}-\pi_{21}^{*}=\frac{g p_{\max }^{2}(a+b)\left(32(a-b) a^{2} g^{2}+16(3 a-2 b) a g p_{\max }+(17 a-7 b) p_{\max }^{2}\right)}{16 a\left(p_{\max }+2 a g\right)^{2}\left(3 p_{\max }+4 a g\right)^{2}} .
$$

Because $a>b, \pi_{22}^{*}-\pi_{21}^{*}>0$.

Equation (28) minus equation (12), we get

$$
\pi_{23}^{*}-\pi_{21}^{*}=\frac{g p_{\max }^{2}\left((2 a-b) p_{\max }+2 a(a-b) g\right)^{2}}{8 a\left(p_{\max }+2 a g\right)\left(p_{\max }+a g\right)\left(3 p_{\max }+4 a g\right)^{2}} .
$$

Because $a>b, \pi_{23}^{*}-\pi_{21}^{*}>0$.

Equation (28) minus equation (20), we get

$$
\pi_{22}^{*}-\pi_{23}^{*}=\frac{g p_{\max }^{2}\left(a g\left(a^{2}+2 a b-3 b^{2}\right)+\left(a^{2}-b^{2}\right) p_{\max }+2 a b p_{\max }\right)}{16 a\left(p_{\max }+a g\right)\left(p_{\max }+2 a g\right)^{2}} .
$$


Because $a>b, \pi_{22}^{*}-\pi_{23}^{*}>0$.

In summary, we know $\pi_{21}^{*}<\pi_{23}^{*}<\pi_{22}^{*}$.

(4) Proofs of Proposition 4
Proof. Based on equations (19) and (20) and equations (33) and (34), we get

$$
\pi_{14}^{*}+\pi_{24}^{*}-\pi_{12}^{*}-\pi_{22}^{*}=\frac{p_{\max }\left(4 a g^{2}(a-b)^{2}+\left(9 a^{2}-6 a b+b^{2}\right) g p_{\max }+4 a p_{\max }^{2}\right)}{16 a\left(p_{\max }+2 a g\right)^{2}} .
$$

Because $a>b, \pi_{14}^{*}+\pi_{24}^{*}-\pi_{12}^{*}-\pi_{22}^{*}>0$.

Based on equations (19) and (20) and equations (33) and (34), we get

$$
\pi_{14}^{*}+\pi_{24}^{*}-\pi_{13}^{*}-\pi_{23}^{*}=\frac{p_{\max }\left(4 a^{2} g^{3}(a-b)^{2}+4 a\left(3 a^{2}-3 a b+b^{2}\right) g^{2} p_{\max }+4 a\left(12 a^{2}-4 a b+b^{2}\right) g p_{\max }^{2}+4 a p_{\max }^{3}\right)}{16 a\left(p_{\max }+a g\right)\left(p_{\max }+2 a g\right)^{2}}
$$

Because $a>b, \pi_{14}^{*}+\pi_{24}^{*}-\pi_{13}^{*}-\pi_{23}^{*}>0$.

From Proposition 2 and Proposition 3, we know $\pi_{11}^{*}+\pi_{21}^{*}-\pi_{12}^{*}-\pi_{22}^{*}<0$, and $\pi_{11}^{*}+\pi_{21}^{*}-\pi_{13}^{*}-$ $\pi_{23}^{*}<0$.
In summary, we know $\pi_{11}^{*}+\pi_{21}^{*}<\pi_{12}^{*}+\pi_{22}^{*}<\pi_{14}^{*}+$ $\pi_{24}^{*}$ and $\pi_{11}^{*}+\pi_{21}^{*}<\pi_{13}^{*}+\pi_{23}^{*}<\pi_{14}^{*}+\pi_{24}^{*}$

(5) Proofs of Proposition 5

Proof. Based on equations (11), (12), (19), (20), (27), (28), (33), and (34), we get

$$
\begin{aligned}
& \frac{\partial \pi_{11}^{*}}{\partial g}=\frac{p_{\max }^{2}(a+b)^{2}\left(3 p_{\max }+2 a g\right)}{a\left(3 p_{\max }+4 a g\right)^{3}}, \\
& \frac{\partial \pi_{21}^{*}}{\partial g}=\frac{\left((2 a-b) p_{\max }+2 a(a-b) g\right)\left(8(a-b) a^{2} g^{2}+2(5 a-7 b) a g p_{\max }+3(2 a-b) p_{\max }^{2}\right)}{a\left(3 p_{\max }+4 a g\right)^{3}} \\
& \frac{\partial \pi_{12}^{*}}{\partial g}=\frac{p_{\max }^{2}(a+b)^{2}}{8 a\left(p_{\max }+2 a g\right)^{2}}, \\
& \frac{\partial \pi_{22}^{*}}{\partial g}=\frac{\left((3 a-b) p_{\max }+4 a(a-b) g\right)\left(8(a-b) a^{2} g^{2}+2(3 a-5 b) a g p_{\max }+(3 a-b) p_{\max }^{2}\right)}{16 a\left(p_{\max }+2 a g\right)^{3}}, \\
& \frac{\partial \pi_{13}^{*}}{\partial g}=\frac{p_{\max }^{2}\left((2 a+b) p_{\max }+2 a(a+b) g\right)\left(4 b a^{2} g^{2}+2(a+2 b) a g p_{\max }+(2 a+b) p_{\max }^{2}\right)}{16 a\left(p_{\max }+2 a g\right)^{3}\left(p_{\max }+a g\right)^{2}}, \\
& \frac{\partial \pi_{23}^{*}}{\partial g}=\frac{\left((2 a-b) p_{\max }+2 a(a-b) g\right)\left(4(a-b) a^{3} g^{3}+2(4 a-5 b) a^{2} g^{2} p_{\max }+6(a-b) a g p_{\max }^{2}+(2 a-b) p_{\max }^{3}\right)}{8 a\left(p_{\max }+2 a g\right)^{2}\left(p_{\max }+a g\right)^{2}} .
\end{aligned}
$$


It is obvious,

$$
\begin{aligned}
& \frac{\partial \pi_{11}^{*}}{\partial g}>0 \\
& \frac{\partial \pi_{12}^{*}}{\partial g}>0 \\
& \frac{\partial \pi_{13}^{*}}{\partial g}>0 .
\end{aligned}
$$

Because $a>b$, therefore, if $5 a-7 b \geq 0$, then $\partial \pi_{21}^{*} / \partial g>0$; if $(3 a-5 b) \geq 0$, then $\partial \pi_{22}^{*} / \partial g>0$; if $(4 a-5 b) \geq 0$, then $\partial \pi_{23}^{*} / \partial g>0$.

In summary, the Proposition 5 holds.

(6) Proofs of Proposition 6

Proof. Based on equation (12), we get

$$
\frac{\partial \pi_{21}^{*}}{\partial a}=\frac{g\left((2 a-b) p_{\max }+2 a(a-b) g\right)\left(8(a+b) a^{2} g^{2}+2(5 a+3 b) a g p_{\max }+3(2 a+b) p_{\max }^{2}\right)}{a^{2}\left(3 p_{\max }+4 a g\right)^{3}}
$$

Because $a>b$, it is obvious that $\partial \pi_{21}^{*} / \partial a>0$.

Based on equation (20), we get

$$
\frac{\partial \pi_{22}^{*}}{\partial a}=\frac{g\left((3 a-b) p_{\max }+4 a(a-b) g\right)\left(8(a+b) a^{2} g^{2}+2(3 a+b) a g p_{\max }+(3 a+b) p_{\max }^{2}\right)}{16 a^{2}\left(p_{\max }+2 a g\right)^{3}}
$$

Because $a>b$, it is obvious that $\partial \pi_{22}^{*} / \partial a>0$.

Based on equation (28), we get

$$
\frac{\partial \pi_{23}^{*}}{\partial a}=\frac{g\left(a^{2} g^{2}+\left(a g+p_{\max }\right)^{2}\right)\left((2 a+b) p_{\max }+2 a(a+b) g\right)\left((2 a-b) p_{\max }+2 a(a-b) g\right)}{8 a^{2}\left(p_{\max }+2 a g\right)^{2}\left(p_{\max }+a g\right)^{2}} .
$$

Because $a>b$, it is obvious that $\partial \pi_{23}^{*} / \partial a>0$.

In summary, the Proposition 6 holds.

(7) Proofs of Proposition 7
Proof. Based on equations (11), (12), (19), (20), (27), (28), (33), and (34), we get

$$
\begin{aligned}
& \frac{\partial \pi_{11}^{*}}{\partial b}=\frac{2 g p_{\max }(a+b)\left(p_{\max }+a g\right)}{a\left(3 p_{\max }+4 a g\right)^{2}} \\
& \frac{\partial \pi_{21}^{*}}{\partial b}=-\frac{2 g\left(p_{\max }+2 a g\right)\left((2 a-b) p_{\max }+2 a(a-b) g\right)}{a\left(3 p_{\max }+4 a g\right)^{2}} \\
& \frac{\partial \pi_{12}^{*}}{\partial b}=\frac{2 g p_{\max }(a+b)}{4 a\left(p_{\max }+2 a g\right)}, \\
& \frac{\partial \pi_{22}^{*}}{\partial b}=-\frac{g\left(p_{\max }+4 a g\right)\left((3 a-b) p_{\max }+4 a(a-b) g\right)}{8 a\left(p_{\max }+2 a g\right)^{2}} \\
& \frac{\partial \pi_{13}^{*}}{\partial b}=\frac{g p_{\max }\left((2 a+b) p_{\max }+2 a(a+b) g\right)}{8 a\left(p_{\max }+2 a g\right)\left(p_{\max }+a g\right)} \\
& \frac{\partial \pi_{23}^{*}}{\partial b}=-\frac{g\left((2 a-b) p_{\max }+2 a(a-b) g\right)}{4 a\left(p_{\max }+a g\right)} .
\end{aligned}
$$


Because $a>b$, it is obvious that $\partial \pi_{11}^{*} / \partial b>0$, $\partial \pi_{12}^{*} / \partial b>0, \partial \pi_{13}^{*} / \partial b>0, \partial \pi_{21}^{*} / \partial b<0, \partial \pi_{22}^{*} / \partial b<0$, and $\partial \pi_{23}^{*} / \partial b<0$.

In summary, the Proposition 7 holds.

\section{Data Availability}

Only the simulation method is used in the study, and the public data set is not used.

\section{Conflicts of Interest}

The authors declare that they have no conflicts of interest.

\section{References}

[1] T. B. Chen and L. T. Chai, "Attitude towards environment and green products: consumers perspective," Management Science and Engineering, vol. 4, no. 2, pp. 27-39, 2010.

[2] J. Sarkis, Q. Zhu, and K.-h. Lai, "An organizational theoretic review of green supply chain management literature," International Journal of Production Economics, vol. 130, no. 1, pp. 1-15, 2011.

[3] D. Ghosh and J. Shah, "A comparative analysis of greening policies across supply chain structures," International Journal of Production Economics, vol. 135, no. 2, pp. 568-583, 2012.

[4] Z. Basiri and J. Heydari, "A mathematical model for green supply chain coordination with substitutable products," Journal of Cleaner Production, vol. 145, pp. 232-249, 2017.

[5] H. Song and X. Gao, "Green supply chain game model and analysis under revenue-sharing contract," Journal of Cleaner Production, vol. 170, pp. 183-192, 2018.

[6] M.-L. Tseng, M. S. Islam, N. Karia, F. A. Fauzi, and S. Afrin, “A literature review on green supply chain management: trends and future challenges," Resources, Conservation and Recycling, vol. 141, pp. 145-162, 2019.

[7] M. Shukla and S. Jharkharia, "Agri-fresh produce supply chain management: a state-of-the-art literature review," International Journal of Operations \& Production Management, vol. 33, no. 2, pp. 114-158, 2013.

[8] I. E. Nielsen, S. Majumder, S. S. Sana, and S. Saha, "Comparative analysis of government incentives and game structures on single and two-period green supply chain," Journal of Cleaner Production, vol. 235, pp. 1371-1398, 2019.

[9] S. Swami and J. Shah, "Channel Coordination in green supply chain management," Journal of the Operational Research Society, vol. 64, no. 3, pp. 336-351, 2013.

[10] D. Yang and T. Xiao, "Pricing and green level decisions of a green supply chain with governmental interventions under fuzzy uncertainties," Journal of Cleaner Production, vol. 149, pp. 1174-1187, 2017.

[11] S. Seuring and M. Müller, "From a literature review to a conceptual framework for sustainable supply chain management," Journal of Cleaner Production, vol. 16, no. 15, pp. 1699-1710, 2008.

[12] H. C. Zhang, T. C. Kuo, H. Lu, and S. H. Huang, "Environmentally conscious design and manufacturing: a state-ofthe-art survey," Journal of Manufacturing Systems, vol. 16, no. 5, pp. 352-371, 1997.

[13] M. Fleischmann, J. M. Bloemhof-Ruwaard, R. Dekker, E. van der Laan, J. A. E. E. van Nunen, and L. N. Van Wassenhove, "Quantitative models for reverse logistics: a review," European Journal of Operational Research, vol. 103, no. 1, pp. 1-17, 1997.

[14] B. M. Beamon, "Designing the green supply chain," Logistics Information Management, vol. 12, no. 4, pp. 332-342, 1999.

[15] S. K. Srivastava, "Green supply-chain management: a state-ofthe-art literature review," International Journal of Management Reviews, vol. 9, no. 1, pp. 53-80, 2007.

[16] S. Luthra, D. Garg, and A. Haleem, "Green supply chain management," Journal of Advances in Management Research, vol. 11, no. 1, pp. 20-46, 2014.

[17] A. P. Jeuland and S. M. Shugan, "Managing channel profits," Marketing Science, vol. 2, no. 3, pp. 239-272, 1983.

[18] S. C. Choi, "Price competition in a channel structure with a common retailer," Marketing Science, vol. 10, no. 4, pp. 271-296, 1991.

[19] S. Chen, X. Wang, L. Ni, and Y. Wu, "Pricing policies in green supply chains with vertical and horizontal competition," Sustainability, vol. 9, no. 12, 2017.

[20] S. A. Raza and S. M. Govindaluri, "Greening and price differentiation coordination in a supply chain with partial demand information and cannibalization," Journal of Cleaner Production, vol. 229, pp. 706-726, 2019.

[21] A. Marshall, Principles of Economics, The Commercial Press, Beijing, China, 1981.

[22] Q. Zhu and Y. Dou, "A game model for GSC management based on government subsidies," Journal of Management Science in China, vol. 14, no. 6, pp. 86-95, 2011. 